Article

\title{
Renewable Energy Investment under Carbon Emission Regulations
}

\author{
Yuan Yuan ${ }^{1,2}$, Feng Cai ${ }^{1, *}$ and Lingling Yang ${ }^{1,3}$ \\ 1 School of Energy and Safety, Anhui University of Science and Technology, Huainan 232001, China; \\ yyuan@hnnu.edu.cn (Y.Y.); yll@htc.edu.cn (L.Y.) \\ 2 School of Economics and Management, Huainan Normal University, Huainan 232001, China \\ 3 Department of Biotechnology, Hefei Technology College, Hefei 238000, China \\ * Correspondence: fcai@aust.edu.cn
}

Received: 4 July 2020; Accepted: 21 August 2020; Published: 24 August 2020

check for updates

\begin{abstract}
This paper considers a risk-neutral energy supplier who operates an electricity plant in an uncertain demand market. To characterize the impact of carbon emission quota and emergency supply cost of coal electricity, we first consider four different cases, (1) traditional energy without carbon emission restriction; (2) traditional energy with carbon emission quota; (3) mixed energy (both traditional and renewable energy) without carbon emission restriction, and (4) mixed energy with carbon emission quota, to find the optimal renewable energy investment level and coal inventory mechanism for an energy supplier. Then, through the analysis we derive the resulting equilibriums: coal inventory for electricity generation and the investment of renewable energy capacity. By comparing the performances under different scenarios, we find that (a) renewable energy establishment can mitigate the depression of carbon emission constraint, (b) the energy supplier can obtain positive benefits from optimal mixed energy strategy if the additional emergency cost of traditional energy is not too high, and (c) the optimal renewable energy capacity level is decreasing in the carbon emission quota. Our numerical simulations imply that the impact of additional emergency cost to the profit difference between mixed energy strategy and traditional energy strategy is mediated by carbon emission quota.
\end{abstract}

Keywords: renewable energy; carbon emission regulations; capacity investment; emergency cost

\section{Introduction}

With the improvement of environmental protection awareness, the issue of greenhouse gas emission is getting more and more attention [1]. The Intergovernmental Panel on Climate Change (IPCC, 2017) reported that global warming is caused by carbon emissions. In response to this dilemma, many countries made some agreements to control emissions of greenhouse gases such as carbon dioxide (e.g., Doha Amendment (2012), Paris Agreement (2015)). One of the most effective mechanisms is carbon emissions quota and transaction supervision. Enterprises can obtain free carbon emission limits in a given period and conduct limit transactions with other companies on the carbon trading market (see [2,3] for example). The Chinese government has begun piloting carbon emissions trading in several administrative regions, where enterprises can obtain free carbon emission caps [4]. In some provinces of China (see Figure 1 for example, data source: China Emission Accounts and Datasets (CEADs)), the increasing speed of both coal consumption and total carbon emission have been slowing down in recent years (e.g., 2013-2015), which indicates that some kinds of energy, especially renewable energy, have begun to take the place of the traditional coal electricity. 


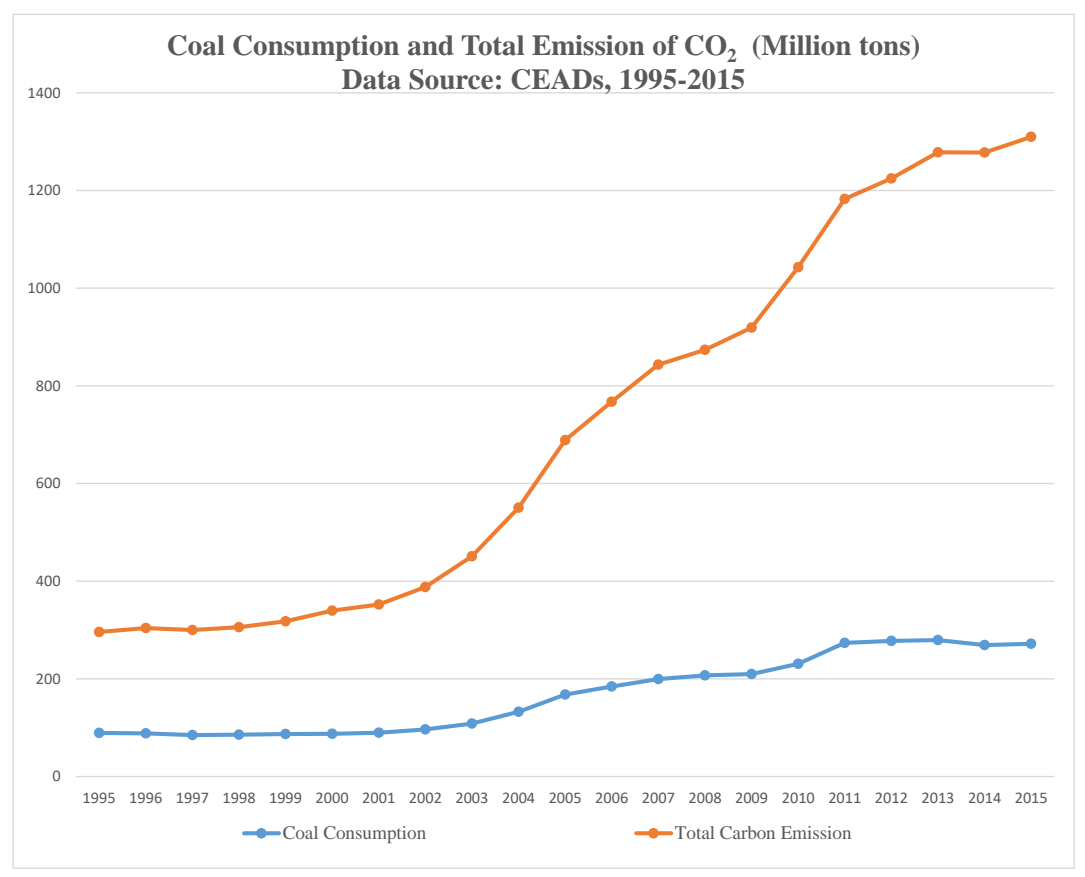

Figure 1. Coal Consumption and Total Emission of $\mathrm{CO}_{2}$ in J Province, China.

This paper considers a risk-neutral energy supplier who operates an electricity plant in an uncertain demand market. To fully characterize the impact of carbon emission quota and emergency supply cost of coal electricity, we first consider four different cases, (1) traditional energy without carbon emission restriction; (2) traditional energy with carbon emission quota; (3) mixed energy (both traditional and renewable energy) without carbon emission restriction, and (4) mixed energy with carbon emission quota, to find the optimal renewable energy capacity investment level and coal inventory mechanism for a traditional energy supplier. Then, we compare the traditional energy strategy and mixed energy strategy to analyze the dominance.

Our contributions to the literature are two-fold. First, taking emergency supply cost of coal electricity into consideration, we design the renewable energy capacity investment level and coal inventory mechanism for a traditional energy supplier in an uncertain demand environment. Second, we study the impact of carbon emission quota, which plays a mediator role in the impact of additional emergency cost to the profit difference and find that the energy supplier can benefit from optimal renewable energy investment in the presence of carbon emission quota.

We arrange the rest of the paper as follows. Section 2 reviews some related literature. In Section 3 , we study the optimal renewable energy investment and coal inventory without carbon emission restriction. Section 4 discusses how to invest renewable energy in the presence of carbon emission quota. In Section 5, we do some numerical simulations. Finally, in Section 6, we make a conclusion.

\section{Literature Review}

Our present work is closely related to the streams on renewable energy, carbon emission constraint, and coal electricity.

In the stream of renewable energy, Kök et al. study the investment in renewable and traditional energy considering the impact of operational flexibility. They give the optimal capacity level of renewable and traditional energy and investigate the interactions between them [5]. Hu et al. investigate a firm's one-time capacity investment in a renewable energy-producing technology, such as wind or solar power. They find some simple computing solutions for investing between renewable and traditional technologies [6]. Sunar and Birge study the strategic commitment of the renewable companies such as wind generators and traditional firms such as coal energy companies in an uncertain market. They characterize companies' equilibrium strategies through 
applying and investigating a supply function competition model [7]. Xie et al. consider the responsive pricing problem for a grid operator in an environment where both supply and demand are uncertain. They evaluate the costs and benefits of flexible procurement and single procurement when generators are strategic price-makers [8]. Goodarzi et al. study the data from the German energy market and investigate the impact of renewable energy (such as wind/solar) forecast errors on unbalanced energy and subsequent spot energy prices [9].

In line with the carbon emission problem, Wang applies the Full-Mrio model to calculate the net value of production-side emissions, consumption-side carbon emissions, and carbon emissions spatial transfer in 30 provinces in China. The net value of domestic carbon emission spatial transfer is allocated, and carbon emission responsibility is shared. Their results show that the spatial transfer of carbon emissions between provinces during the study period is very significant [10]. Through theoretical discussion and empirical testing, Lv and Zhang find that there is significant carbon transfer between Chinese provinces, and the carbon intensity of each province varies greatly [11]. Zhu investigates the impact of government regulation and market trading on carbon emission, and the results show that the former can impact the firms' carbon emission behavior [12]. Qin et al. consider the carbon emission reduction of manufacturers with limited funds, considering the quota and trading system, and their research shows that green financial interest rates do not always have a negative impact on manufacturers' carbon emission reductions [4].

In the stream of coal electricity, Da et al. employ the cap-and-trade model in a green financial policy back ground to develop optimal strategy for the coal-electric power supply chain, and find that, in the context of green finance, the high discount rate of bank loans that invest in carbon reduction technologies is equivalent to a large amount of carbon reduction by coal companies, a large amount of heat energy ordered by power companies, and high profits for coal power companies [13]. Zhao et al. discuss whether the establishment of a cooperative relationship between the coal supplier and the electricity company can resolve the conflict of interest between them. The results of their study indicate that the associated contractual behavior among power companies improves the market performance of power companies [14]. Fan et al. employ a Stackelberg model to study two kinds of coal electricity price linkage policies, and their results show that the coal electricity price linkage policy is conducive to reducing the profit loss of coal-fired power plants during the rise in coal prices [15]. For more on the latest findings about carbon emission and coal electricity, please see [16-21] and the references therein.

Different from the existing literature mentioned above, the present work takes carbon emission restriction and emergency supply cost into consideration, focusing on the investment in the renewable energy capacity, which is a supplementary choice for the traditional power supplier.

\section{Model Description}

We consider a risk-neutral energy supplier (ES) who sells electricity to an uncertain demand market. The conventional energy supplier buys fuel (e.g., coal) to generate electricity; we call this kind of energy traditional energy (denote by TE). With the improvement of environmental protection awareness, more and more consumers prefer using renewable energy (denote by RE). In order to satisfy the consumers' demand, the energy supplier may establish the solar/wind power stations to generate renewable energy.

In the consumer market, the electricity demand $D$ is uncertain, with mean $\mu$ and standard deviation $\sigma$, we denote its probability density function (PDF) by $f(\cdot)$, the cumulative distribution function $(\mathrm{CDF})$ by $F(\cdot)$, and the complementary cumulative distribution function (CCDF) by $\bar{F}(\cdot)$. We assume that the demand distribution has a strictly increasing generalized failure rate (IGFR), i.e., $z f(z) / \bar{F}(z)$ is increasing in $z$. This kind of distribution has been widely used in many studies, such as [22-24]. Many common distributions are IGFR, for instance, the uniform, normal, exponential, gamma. There is no asymmetric information between players. 
To produce the traditional electricity, the energy supplier will make the coal procurement, which costs $c$ per unit power (e.g., KWH). Denote $k_{s}$ by the RE station fixed setup cost, where $s$ denotes the RE station capacity (i.e., total units of the electricity that the RE station can supply). Since solar and wind account for the majority of the renewable energy output, we assume that the renewable energy unit margin cost is negligible (see [5] for the same assumption). However, once the RE station is established, the total capacity can hardly change. Therefore, the RE station capacity is an important issue for an electricity plant: large capacity needs more setup cost but can satisfy more consumers and the reverse. Since the energy demand is unclear before the coal procurement, ES will make the procurement carefully. If the realized demand is less than the prepared electricity, the redundant energy will be discarded. If the realized demand is more than the prepared electricity, the ES will make the emergency supply, which will cost additional $\operatorname{cost} \delta \geq 0$ per unit power, i.e., the emergency unit power cost is $\tilde{c}=c+\delta$. Since the emergency power comes from the other plants, we assume that the emergency power will not generate any carbon emission for the ES. The electricity price is $p$, which is exogenous due to market competition.

The action/decision sequence is shown in Figure 2: At the beginning (time $T_{0}$ ), ES decides whether or not to establish the renewable energy station; If yes, ES first decides the renewable energy station capacity and then makes coal procurement (at time $T_{1}$ ); Otherwise, ES will prepare the coal to produce the traditional energy (at time $T_{1}$ ). After that, the demand is realized, and ES supplies the electricity accordingly. Finally, ES collects the revenue at time $T_{2}$.

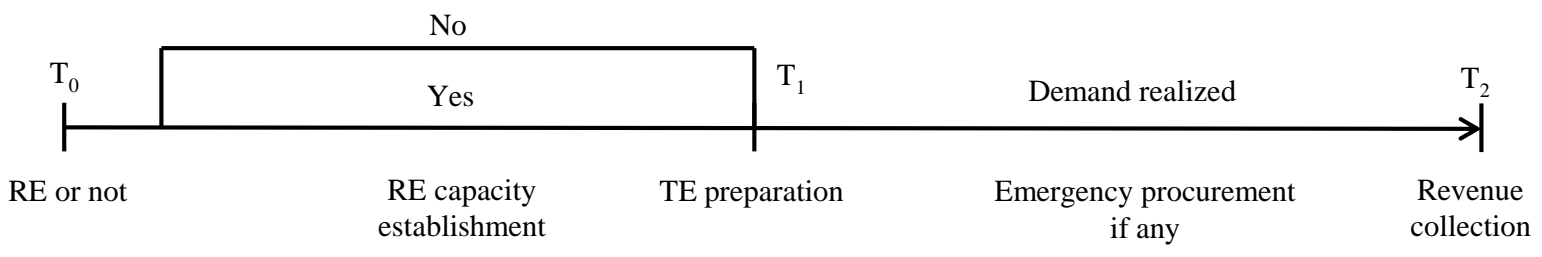

Figure 2. Timeline of the sequence.

\subsection{Basic Model: TE Without Carbon Emission Constraint}

If energy supplier decides to supply the traditional energy only, the problem becomes a classical newsvendor problem, and the ES becomes the power vendor. In this case, ES only needs to prepare the optimal amount of electricity $q$, and its problem is

$$
\max _{q \geq 0} \quad \pi_{\mathrm{TE}}(q)=p \mathbb{E}[D]-c q-\tilde{c} \mathbb{E}[D-q]^{+},
$$

or equivalently,

$$
\max _{q \geq 0} \pi_{\mathrm{TE}}(q)=p \mu-c q-\tilde{c} \int_{q}^{+\infty}(y-q) f(y) d y,
$$

where $\pi_{\mathrm{TE}}$ denotes the energy supplier's expected profit under TE strategy, $\mathbb{E}[\cdot]$ denotes the expectation operator, and $[a]^{+}=\max \{0, a\}$.

Lemma 1. $\frac{d^{2}}{d q^{2}} \pi_{T E}(q)<0$.

Proof. Since $\frac{d}{d q} \pi_{\mathrm{TE}}(q)=-c+\tilde{c} \bar{F}(q)$, and $\frac{d^{2}}{d q^{2}} \pi_{\mathrm{TE}}(q)=-\tilde{c} f(q)$. Since the $f(\cdot)$ is the probability density function, which is always non-negative, hence $\frac{d^{2}}{d q^{2}} \pi_{\mathrm{TE}}(q) \leq 0$, Lemma 1 follows. 
Lemma 1 implies that $\pi_{\mathrm{TE}}(q)$ is concave in $q$, according to the first order condition (FOC), i.e., $\frac{d}{d q} \pi_{\mathrm{TE}}(q)=-c+\tilde{c} \bar{F}(q)=0$, the optimal coal inventory is

$$
q^{*}=\bar{F}^{-1}(c / \tilde{c}) .
$$

Substituting (3) into ES's profit function (2), we have the ES's optimal profit

$$
\pi_{\mathrm{TE}}^{*}=\pi_{\mathrm{TE}}\left(q^{*}\right)=p \mu-c \bar{F}^{-1}(c / \tilde{c})-\tilde{c} \int_{\bar{F}^{-1}(c / \tilde{c})}^{+\infty}\left(y-\bar{F}^{-1}(c / \tilde{c})\right) f(y) d y .
$$

\subsection{TE with Carbon Emission Constraint}

When the ES faces the carbon emission quota $\bar{q}$, under the traditional energy strategy, it only needs to prepare the optimal amount of electricity $q \leq \bar{q}$, and the ES's problem becomes

$$
\begin{aligned}
\max _{q \geq 0} \quad \pi_{\mathrm{TE}}(q) & =p \mathbb{E}[D]-c q-\tilde{c} \mathbb{E}[D-q]^{+} \\
& =p \mu-c q-\tilde{c} \int_{q}^{+\infty}(y-q) f(y) d y .
\end{aligned}
$$

subject to $q \leq \bar{q}$.

Since $\pi_{\mathrm{TE}}(q)$ is concave, and increasing in $q$ when $q \leq \bar{F}^{-1}\left(\frac{c}{\tilde{\tilde{c}}}\right)$ (see Figure 3), then the optimal $q$ to above problem is

$$
q^{*}=\min \left\{\bar{F}^{-1}\left(\frac{c}{\tilde{c}}\right), \bar{q}\right\}
$$

That is, if $\bar{F}^{-1}\left(\frac{\mathcal{c}}{\tilde{c}}\right) \leq \bar{q}$, then the optimal coral inventory is the same as the case without emission constraint, otherwise, the optimal coral inventory level binding the constraint $q \leq \bar{q}$, i.e., $q^{*}=\bar{q}$. Hence, for given carbon emission quota $\bar{q} \geq 0$, the maximum expected profit is

$$
\pi_{\mathrm{TE}}^{*}=\pi_{\mathrm{TE}}(\bar{q})= \begin{cases}p \mu-c \bar{q}-\tilde{c} \int_{\bar{q}}^{+\infty}(y-\bar{q}) f(y) d y, & \text { if } 0 \leq \bar{q}<\bar{F}^{-1}(c / \tilde{c}) \\ p \mu-c \bar{F}^{-1}\left(\frac{c}{\tilde{c}}\right)-\tilde{c} \int_{\bar{F}^{-1}\left(\frac{c}{\tilde{c}}\right)}^{+\infty}\left(y-\bar{F}^{-1}\left(\frac{c}{\tilde{c}}\right)\right) f(y) d y, & \text { if } \bar{q} \geq \bar{F}^{-1}(c / \tilde{c}) .\end{cases}
$$
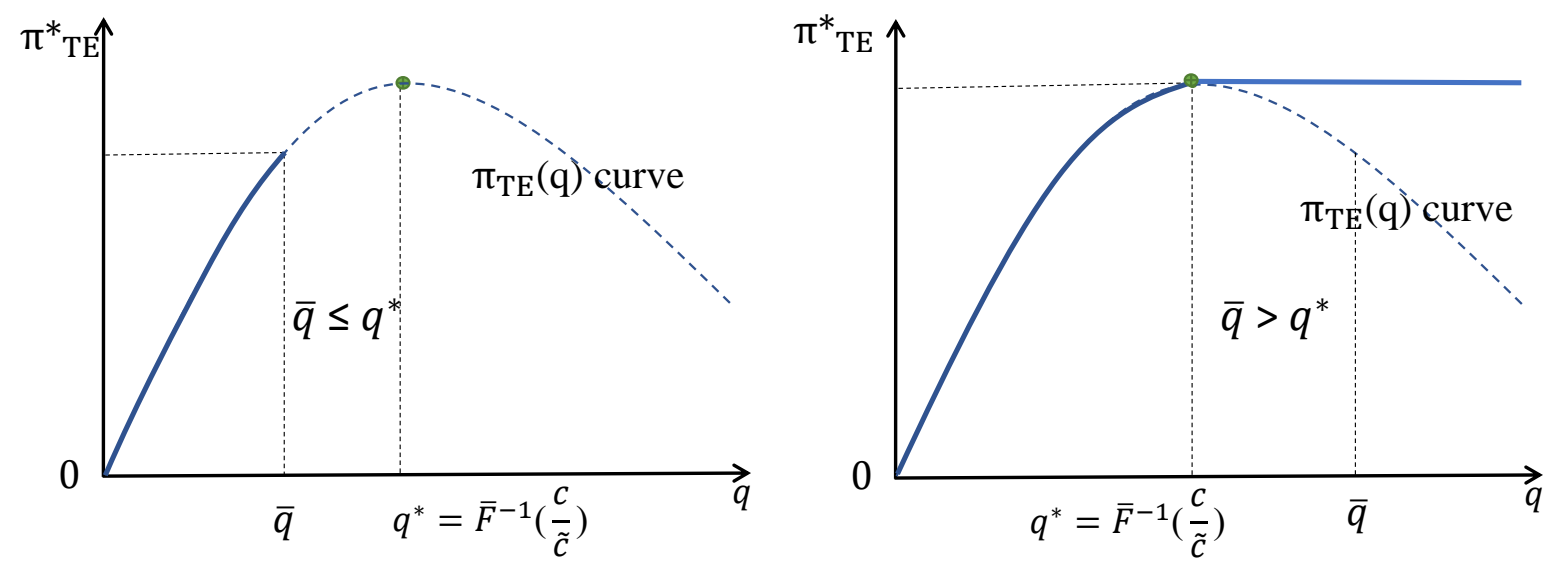

Figure 3. Expected Profit with Carbon Emission Quota.

It can be found that the optimal profit $\pi_{\mathrm{TE}}^{*}$ is increasing in $\bar{q}$ when $\bar{q}<\bar{F}^{-1}(c / \tilde{c})$, hence, the optimal profit in the presence of carbon emission quota is lower than (or equal with) that without quota. 


\section{Mixed Model: TE and RE (TR)}

\subsection{TR without Carbon Emission Constraint}

If energy supplier establishes the renewable energy plant, then the setup investment $k_{s}$ depends on the electricity capacity $s$, which can generate $s$ unit (e.g., $s \mathrm{KWH}$ ) electricity. We assume that $k_{0}=0$, and $k_{s}$ is increasing and convex in $s$, i.e., $k_{s}^{\prime} \geq 0$ and $k_{s}^{\prime \prime} \geq 0$. Under this strategy, the ES needs to decide the capacity $s$ (or equivalently decide investment level $k_{s}$ due to the one-to-one relationship between $s$ and $k_{s}$ ) and the coal inventory level, $q_{\mathrm{TR}}$. Then the ES's expected profit is

$$
\pi_{\mathrm{TR}}\left(q_{\mathrm{TR}}, s\right)=p \mathbb{E}[D]-c q_{\mathrm{TR}}-\tilde{c} \mathbb{E}\left[D-q_{\mathrm{TR}}-s\right]^{+}-k_{s} .
$$

Therefore, the ES's problem is

$$
\max _{q_{\mathrm{TR}} \geq 0, s \geq 0} \pi_{\mathrm{TR}}\left(q_{\mathrm{TR}}, s\right)=p \mu-c q_{\mathrm{TR}}-\tilde{c} \int_{q_{\mathrm{TR}}+s}^{+\infty}\left(y-q_{\mathrm{TR}}-s\right) f(y) d y-k_{s} .
$$

Denote the Hessian matrix of $\pi_{\mathrm{TR}}\left(q_{\mathrm{TR}}, s\right)$ to be

$$
\mathbf{H}_{\mathrm{TR}}=\left(\begin{array}{cc}
\frac{\partial^{2} \pi_{\mathrm{TR}}}{\partial \mathrm{S}^{2}}\left(q_{\mathrm{TR}}, s\right) & \frac{\partial^{2} \pi_{\mathrm{TR}}}{\partial s \partial_{\mathrm{TR}}}\left(q_{\mathrm{TR}}, s\right) \\
\frac{\partial^{2} \pi_{\mathrm{TR}}}{\partial q_{\mathrm{TR}} \partial_{\mathrm{s}}}\left(q_{\mathrm{TR}}, s\right) & \frac{\partial^{2} \pi_{\mathrm{TR}}}{\partial q_{\mathrm{TR}}}\left(q_{\mathrm{TR}}, s\right)
\end{array}\right) .
$$

Lemma 2. The Hessian matrix $\mathbf{H}_{\mathrm{TR}}$ is negative definite.

Proof. From (9), we have

$$
\frac{\partial \pi_{\mathrm{TR}}}{\partial s}\left(q_{\mathrm{TR}}, s\right)=\tilde{c} \bar{F}\left(q_{\mathrm{TR}}+s\right)-k_{s}^{\prime}, \quad \frac{\partial \pi_{\mathrm{TR}}}{\partial q_{\mathrm{TR}}}\left(q_{\mathrm{TR}}, s\right)=-c+\tilde{c} \bar{F}\left(q_{\mathrm{TR}}+s\right),
$$

and then

$$
\begin{aligned}
& \frac{\partial^{2} \pi_{\mathrm{TR}}}{\partial s^{2}}\left(q_{\mathrm{TR}}, s\right)=-\tilde{c} \bar{F}\left(q_{\mathrm{TR}}+s\right)-k_{s}^{\prime \prime}, \\
& \frac{\partial^{2} \pi_{\mathrm{TR}}}{\partial q_{\mathrm{TR}}^{2}}\left(q_{\mathrm{TR}}, s\right)=-\tilde{c} \bar{F}\left(q_{\mathrm{TR}}+s\right), \\
& \frac{\partial^{2} \pi_{\mathrm{TR}}}{\partial s d q_{\mathrm{TR}}}\left(q_{\mathrm{TR}}, s\right)=-\tilde{c} \bar{F}\left(q_{\mathrm{TR}}+s\right) .
\end{aligned}
$$

Hence, we have the Hessian matrix is

$$
\mathbf{H}_{\mathrm{TR}}=\left(\begin{array}{cc}
-\tilde{c} f\left(q_{\mathrm{TR}}+s\right) & -\tilde{c} f\left(q_{\mathrm{TR}}+s\right) \\
-\tilde{c} f\left(q_{\mathrm{TR}}+s\right) & -\tilde{c} f\left(q_{\mathrm{TR}}+s\right)-k_{s}^{\prime \prime}
\end{array}\right)
$$

which is a negative definite matrix since the positivity of $f(\cdot)$ and the convexity of $k_{s}$.

Therefore, $\pi_{\mathrm{TR}}\left(q_{\mathrm{TR}}, s\right)$ have unique maximum solution, denote by $\left(q_{\mathrm{TR}}^{*} s^{*}\right)$, which solve

$$
\frac{\partial \pi_{\mathrm{TR}}}{d s}\left(q_{\mathrm{TR}}, s\right)=\tilde{c} \bar{F}\left(q_{\mathrm{TR}}+s\right)-k_{s}^{\prime}=0, \quad \frac{\partial \pi_{\mathrm{TR}}}{d q_{\mathrm{TR}}}\left(q_{\mathrm{TR}}, s\right)=-c+\tilde{c} \bar{F}\left(q_{\mathrm{TR}}+s\right)=0 .
$$

Then we arrive at the following proposition. 
Proposition 1. Under TR strategy, the optimal RE investment level $k_{s^{*}}$ and coal inventory $q_{T R}^{*}$ satisfy

$$
k_{s^{*}}^{\prime}=c, \quad \text { and } \quad q_{T R}^{*}= \begin{cases}\bar{F}^{-1}(c / \tilde{c})-s^{*}, & \text { if } s^{*} \leq \bar{F}^{-1}(c / \tilde{c}) \\ 0, & \text { otherwise. }\end{cases}
$$

respectively.

Proof. From Equation (16) we have

$$
\tilde{c} \bar{F}\left(q_{\mathrm{TR}}+s\right)=k_{s}^{\prime}, \quad \text { and } \quad \bar{F}\left(q_{\mathrm{TR}}+s\right)=c / \tilde{c},
$$

substitute the later into the former we have Proposition 1 holds.

Proposition 1 gives the optimal renewable investment level and coal inventory under TR strategy. Specifically, under such strategy, on the one hand, the last coin invested in the renewable energy should equal to the coal margin cost (i.e., $k_{s^{*}}^{\prime}=c$ ); on the other hand, the optimal coal inventory decision should take unit emergency procurement cost and renewable energy capacity into consideration. Moreover, the larger unit emergency procurement cost is, the less coal inventory will be prepared.

Proposition 2. Under TR strategy, when $\delta \geq \frac{c}{\bar{F}\left(\left(k_{s^{*}}^{\prime}\right)^{-1}(c)\right)}-c$, the optimal coal inventory is $q_{T R}^{*}=0$, where $\left(k_{s^{*}}^{\prime}\right)^{-1}(\cdot)$ denotes the inverse function of $k_{s^{*}}^{\prime}$.

Proof. According to Proposition 1 and the convex-increasing investment cost $k_{s}$, then $s^{*}=\left(k_{s^{*}}^{\prime}\right)^{-1}(c)$. Substitute $s^{*}=\left(k_{s^{*}}^{\prime}\right)^{-1}(c)$ into $q_{\mathrm{TR}}^{*}$ we have, $\bar{F}^{-1}(c / \tilde{c})-s^{*} \leq 0$ if $\tilde{c} \geq \frac{c}{\bar{F}\left(s^{*}\right)}$, which implies that $\delta \geq \frac{c}{\bar{F}\left(s^{*}\right)}-c$.

Consistent with Proposition 1, Proposition 2 suggests that, under TR strategy, when the emergency procurement cost is high enough, energy supplier will never prepare any coal. This is because the renewable energy can mitigate the loss of mismatch between demand and supply. For energy supplier, the higher emergency procurement cost means it may face more shortage cost, which will result in energy supplier lowering the coal electricity supply and expanding renewable energy capacity.

Substituting (17) into ES's profit function (9), we have

$$
\pi_{\mathrm{TR}}^{*}=\pi_{\mathrm{TR}}\left(q^{*}\right)=p \mu-c \bar{F}^{-1}(c / \tilde{c})-\tilde{c} \int_{\bar{F}^{-1}(c / \tilde{c})}^{+\infty}\left(y-\bar{F}^{-1}(c / \tilde{c})\right) f(y) d y+c s^{*}-k_{s^{*}} .
$$

Denote $\Delta \pi_{\mathrm{TE}}^{\mathrm{TR}}=\pi_{\mathrm{TR}}^{*}-\pi_{\mathrm{TE}}^{*}$, then $\Delta \pi_{\mathrm{TE}}^{\mathrm{TR}}=c s^{*}-k_{\mathrm{S}^{*}}$, then we have following property.

Property 1. $\Delta \pi_{T E}^{T R}=c s^{*}-k_{s^{*}} \geq 0$.

Proof. Since $k_{s}$ is convex-increasing in $s \geq 0$ with $k_{0}=0$, then $k_{s}^{\prime}$ is increasing in $s$, hence $0 \leq k_{s}^{\prime} \leq c$ as $s \leq s^{*}$. Therefore, $k_{s} \leq c s$ when $0 \leq s \leq s^{*}$, which implies Property 1 .

Property 1 implies that, without carbon emission constraint, under the optimal renewable energy investment and coal inventory, ES's expected profit under TR strategy is always greater than that of TE strategy, with a positive benefit (see Figure 4). However, as the following section indicates, we will show that this scenario will change in the presence of carbon emission constraint. 


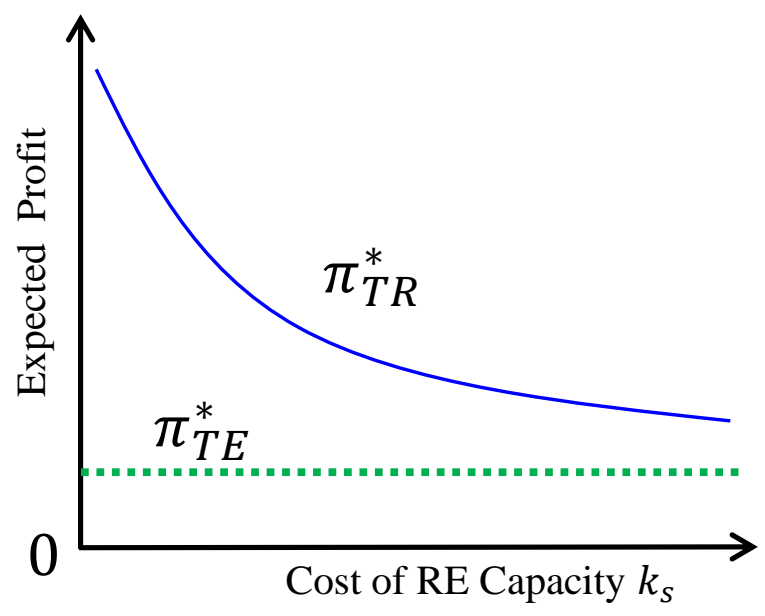

Figure 4. TR vs. TE without carbon emission quota.

\subsection{TR with Carbon Emission Constraint}

Since if $\bar{q} \geq \bar{F}^{-1}(c / \tilde{c})$, then the optimal coal inventory is the same as the case without any carbon emission constraint, therefore, we assume that $\bar{q}<\bar{F}^{-1}(c / \tilde{c})$ in this section, and then the ES's problem becomes

$$
\begin{gathered}
\max _{q_{\mathrm{TR}} \geq 0, s \geq 0} \pi_{\mathrm{TR}}\left(q_{\mathrm{TR}}, s\right)=p \mu-c q_{\mathrm{TR}}-\tilde{c} \int_{q_{\mathrm{TR}}+s}^{+\infty}\left(y-q_{\mathrm{TR}}-s\right) f(y) d y-k_{s}, \\
\text { subject to } q_{\mathrm{TR}} \leq \bar{q} .
\end{gathered}
$$

Proposition 3. For given carbon emission quota $0 \leq \bar{q}<\bar{F}^{-1}(c / \tilde{c})$, the optimal RE investment level $k_{s^{*}}$ and coal inventory $q_{T R}^{*}$ satisfy, respectively,

$$
\tilde{c} \bar{F}\left(\bar{q}+s^{*}\right)=k_{s^{*}}^{\prime}
$$

and

$$
q_{T R}^{*}= \begin{cases}\bar{q}, & \text { if } s^{*}<\bar{F}^{-1}(c / \tilde{c})-\bar{q} \\ \bar{F}^{-1}(c / \tilde{c})-s^{*}, & \text { if } \bar{F}^{-1}(c / \tilde{c})-\bar{q} \leq s^{*}<\bar{F}^{-1}(c / \tilde{c}) \\ 0, & \text { if } s^{*} \geq \bar{F}^{-1}(c / \tilde{c}) .\end{cases}
$$

Proof. Applying the same method with TR without carbon emission quota, we know that the Hessian matrix of $\pi_{\mathrm{TR}}\left(q_{\mathrm{TR}}, s\right)$ is negative definite too. The constraint is linear in $q$; we can solve the above problem by using the KKT condition. Let $\lambda$ be the Lagrange multiplier associated with the constraint. Then Lagrange function is

$$
£(q, s ; \lambda)=p \mu-c q_{\mathrm{TR}}-\tilde{c} \int_{q_{\mathrm{TR}}+s}^{+\infty}\left(y-q_{\mathrm{TR}}-s\right) f(y) d y-k_{s}+\lambda \cdot(q-\bar{q}) .
$$

It follows from the KKT condition (taking the derivative of the Lagrange function with respect to $q, \lambda$ and $s$, respectively), that the optimal value of $q$ and $s$ is given by

$$
q=\bar{q}, \quad \text { and } \quad \tilde{c} \bar{F}(q+s)=k_{s}^{\prime} .
$$

Substituting $q=\bar{q}$ into $\tilde{c} \bar{F}(q+s)=k_{s}^{\prime}$, we have

$$
\tilde{c}=\frac{k_{s}^{\prime}}{\bar{F}(\bar{q}+s)}
$$


the right hand side of which is increasing in $s$, then for any $\tilde{c}$ and $\bar{q}$, there exists unique $s^{*}$ such that above equation holds, that is (21) holds.

Now we move to analysis of the optimal coal inventory $q_{\mathrm{TR}}^{*}$. If the optimal $s^{*} \geq \bar{F}^{-1}(c / \tilde{c})$, which means the renewable energy setup cost is very low, then the ES will only choose the renewable energy strategy to satisfy the consumer market and prepare zero coal inventory. If $\bar{F}^{-1}(c / \tilde{c})-\bar{q} \leq s^{*}<\bar{F}^{-1}(c / \tilde{c})$, that is, the setup cost is moderate, then this case is the same as that without any carbon emission constraint, the optimal coal inventory is $\bar{F}^{-1}(c / \tilde{c})-s^{*}$. If $s^{*}<\bar{F}^{-1}(c / \tilde{c})-\bar{q}$, which means that the setup cost is very high, then the ES will prepare the coal inventory level the same as the quota, and the unmet demand will be satisfied from the emergency market.

As is analyzed in the proof, Proposition 3 indicates that, when the carbon emission quota is low and the renewable energy setup cost is high, then the ES will only prepare $q_{\mathrm{TR}}^{*}+s^{*}$, which is less than the optimal supply $\bar{F}^{-1}(c / \tilde{c})$. Otherwise, ES will prepare the total electricity equals optimal supply $\bar{F}^{-1}(c / \tilde{c})$.

Property 2. $\frac{d s^{*}}{d \bar{q}}<0$.

Proof. By Equation (21) and implicit function theorem, we have

$$
\frac{d s^{*}}{d \bar{q}}=-\frac{\tilde{c} f\left(\bar{q}+s^{*}\right)}{k_{s^{*}}^{\prime \prime}+\tilde{c} f\left(\bar{q}+s^{*}\right)}<0,
$$

which is because $k_{s^{*}}^{\prime \prime} \geq 0$.

Property 2 indicates that the optimal renewable energy capacity investment reverse varies with the carbon emission quota. If the carbon emission quota is small, in order to gain more revenue, the ES has to enlarge the supply to the market, then expanding the renewable energy capacity is the only option. While if a large emission quota is obtained, the ES will make the trade-off between purchasing more coal for traditional energy or establishing larger renewable energy capacity, then a smaller capacity renewable energy station will be established. Hence, by (21) and (22), for given carbon emission quota, the maximum expected profit is

$$
\begin{aligned}
& \pi_{\mathrm{TR}}^{*}(\bar{q})=\pi_{\mathrm{TR}}\left(q_{\mathrm{TR}}^{*} s^{*} ; \bar{q}\right)=p \mu-c q_{\mathrm{TR}}^{*}-\tilde{c} \int_{q_{\mathrm{TR}}^{*}+s^{*}}^{+\infty}\left(y-q_{\mathrm{TR}}^{*}-s^{*}\right) f(y) d y-k_{s^{*}} \\
& = \begin{cases}p \mu-c \bar{q}-\tilde{c} \int_{\bar{q}+s^{*}}^{+\infty}(y-\bar{q}) f(y) d y & \text { if } s^{*}<\bar{F}^{-1}(c / \tilde{c})-\bar{q} ; \\
+\tilde{c} s^{*} \bar{F}\left(\bar{q}+s^{*}\right)-k_{s^{*}}, & \\
p \mu-\tilde{c} \int_{\bar{F}^{-1}(c / \tilde{c})}^{+\infty}\left(y-\bar{F}^{-1}(c / \tilde{c})\right) f(y) d y \\
-c \bar{F}^{-1}(c / \tilde{c})+c s^{*}-k_{s^{*}}, & \text { if } \bar{F}^{-1}(c / \tilde{c})-\bar{q} \leq s^{*}<\bar{F}^{-1}(c / \tilde{c}) .\end{cases}
\end{aligned}
$$

or equivalently,

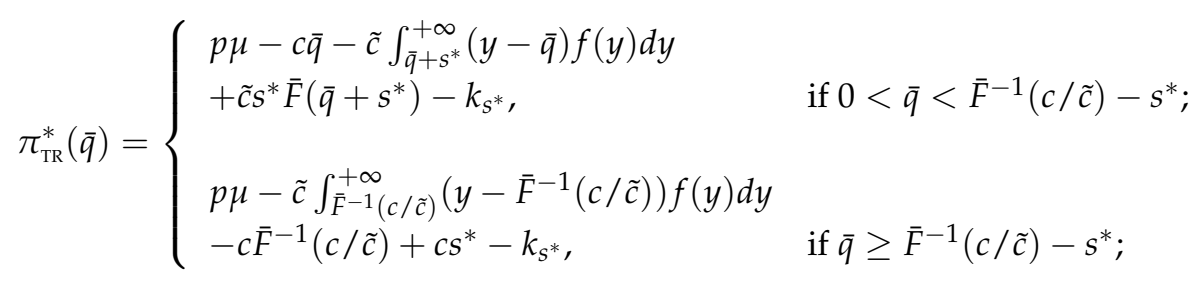


Let $\Delta \prod_{\mathrm{TE}}^{\mathrm{TR}}(\bar{q})$ denote the profit difference between TE and TR with the carbon emission quota. Then by (7) and (26), we have

$$
\begin{aligned}
& \Delta \prod_{\mathrm{TE}}^{\mathrm{TR}}(\bar{q})=\pi_{\mathrm{TR}}^{*}(\bar{q})-\pi_{\mathrm{TE}}^{*}(\bar{q}) \\
& = \begin{cases}\tilde{c} s^{*} \bar{F}\left(\bar{q}+s^{*}\right)-k_{s^{*}}+\tilde{c} \int_{\bar{q}}^{\bar{q}+s^{*}}(y-\bar{q}) f(y) d y, & \text { if } 0<\bar{q} \leq \bar{F}^{-1}(c / \tilde{c})-s^{*} ; \\
c s^{*}-k_{s^{*}}+\tilde{c} \int_{\bar{q}}^{\bar{F}^{-1}(c / \tilde{c})}(y-\bar{q}) f(y) d y, & \text { if } \bar{F}^{-1}(c / \tilde{c})-s^{*}<\bar{q} \leq \bar{F}^{-1}(c / \tilde{c}) .\end{cases}
\end{aligned}
$$

Property 3. $\Delta \prod_{T E}^{T R}(\bar{q})-\Delta \pi_{T E}^{T R} \geq 0$.

Proof. The proof of Property 3 is similar to that of Property 1 , so we omit it here.

Proposition 3 suggests when and how to establish the renewable energy capacity under carbon emission regulations. Firstly, if the ES finds that it is beneficial to invest renewable energy when there is no carbon emission constraint, then it should establish renewable energy when there is carbon emission constraint. Secondly, together with Property 2, when the carbon emission quota is large enough (e.g., $\left.\bar{q}>\bar{F}^{-1}(c / \tilde{c})-s^{*}\right)$, the ES will establish the same renewable energy capacity as that without carbon emission constraint.

\section{Numerical Simulation}

In this section, we will investigate the impact of additional emergency cost and carbon emission quota and do the numerical experiments to examine the results we have obtained in the previous sections. Noting that normal distribution is IGFR, in order to simplify the calculation, we assume that the energy demand $D$ is with $D \sim N\left(\mu, \sigma^{2}\right)$, where $N(\cdot, \cdot)$ denotes the normal distribution, $\mu$ and $\sigma$ denote the mean and standard deviation, respectively. That is, $F=N(\cdot, \cdot)$. For the standard normal distribution $N(0,1)$, we denote its probability density function (PDF) by $\phi(\cdot)$, the cumulative distribution function $(\mathrm{CDF})$ by $\Phi(\cdot)$, and the complementary cumulative distribution function (CCDF) by $\bar{\Phi}(\cdot)$. In this section, without additional statements, we set $\mu=5, \sigma=1$, $c=2, p=5$ and $k_{s}=\frac{1}{2} s^{2}$, and then the optimal coal inventory without carbon emission quota is $q^{*}=\mu+z^{*} \sigma=5+\bar{\Phi}^{-1}(2 /(2+\delta))$, where $\delta$ denotes the unit additional emergency cost, i.e., $\delta=\tilde{c}-c$ (see more notations in Abbreviation).

\subsection{Impact of Additional Emergency Cost}

This section investigates the impact of additional emergency cost for given carbon emission quota. The additional emergency cost is harmful to both TE and TR strategy, as is shown in Figure 5 . Specifically, when the carbon emission quota is small $(\bar{q}=2)$, the expected profit under TE and TR strategy first decreases and then becomes flat (zero profit). Noting that for some additional emergency cost (for example, $\delta>5$, left figure of Figure 5), TE strategy cannot bring any positive profit to ES, hence, the TE strategy will be abandoned if the additional emergency cost is high. When the carbon emission quota is large ( $\bar{q}=5.5)$, TE strategy is also dominated by TR strategy.

Figure 6 describes the profit difference between TR and TE strategy. We can find that the additional emergency cost plays an important role in profit difference, and such impact is mediated by the carbon emission quota. When the carbon emission quota is small $(\bar{q}=2)$, the profit difference is quasi-concave, and first increasing, then decreasing and finally flat (left figure of Figure 6) as additional emergency cost increases. Differently, when the carbon emission quota is large $(\bar{q}=5.5)$, the profit difference is quasi-convex, and first decreasing, then increasing as additional emergency cost goes up. 

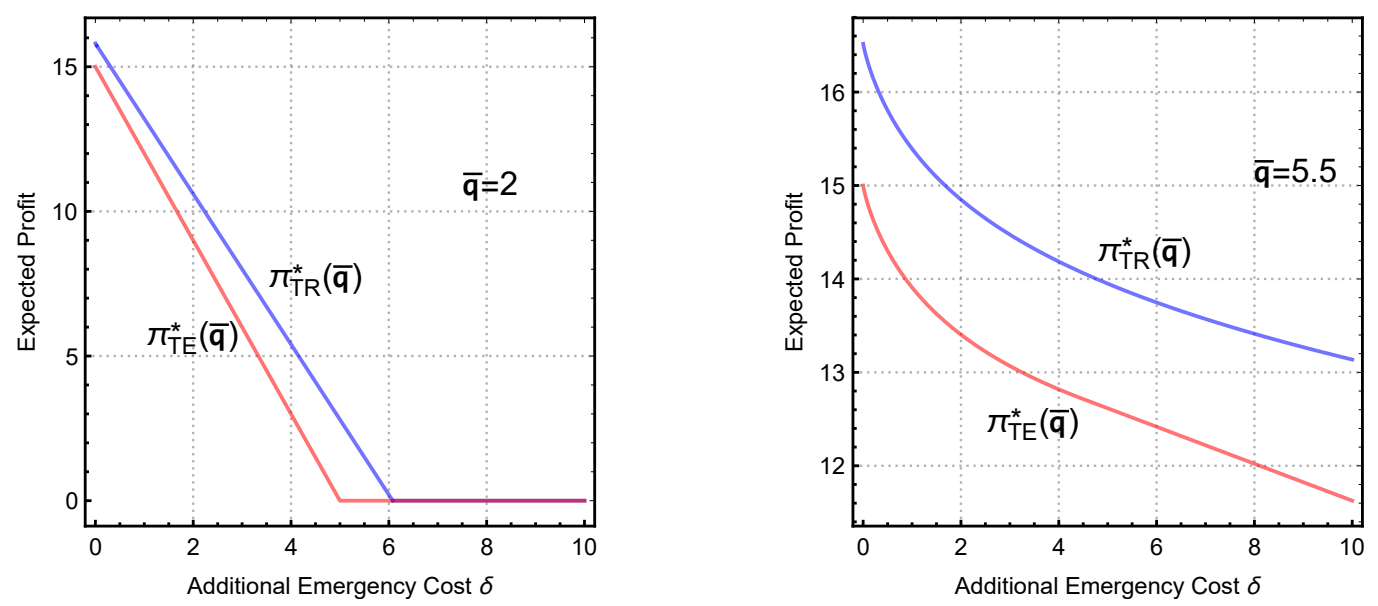

Figure 5. Expected profit $\pi_{\mathrm{TR}}^{*}(\bar{q})$ and $\pi_{\mathrm{TE}}^{*}(\bar{q})$ in additional emergency $\operatorname{cost} \delta$.
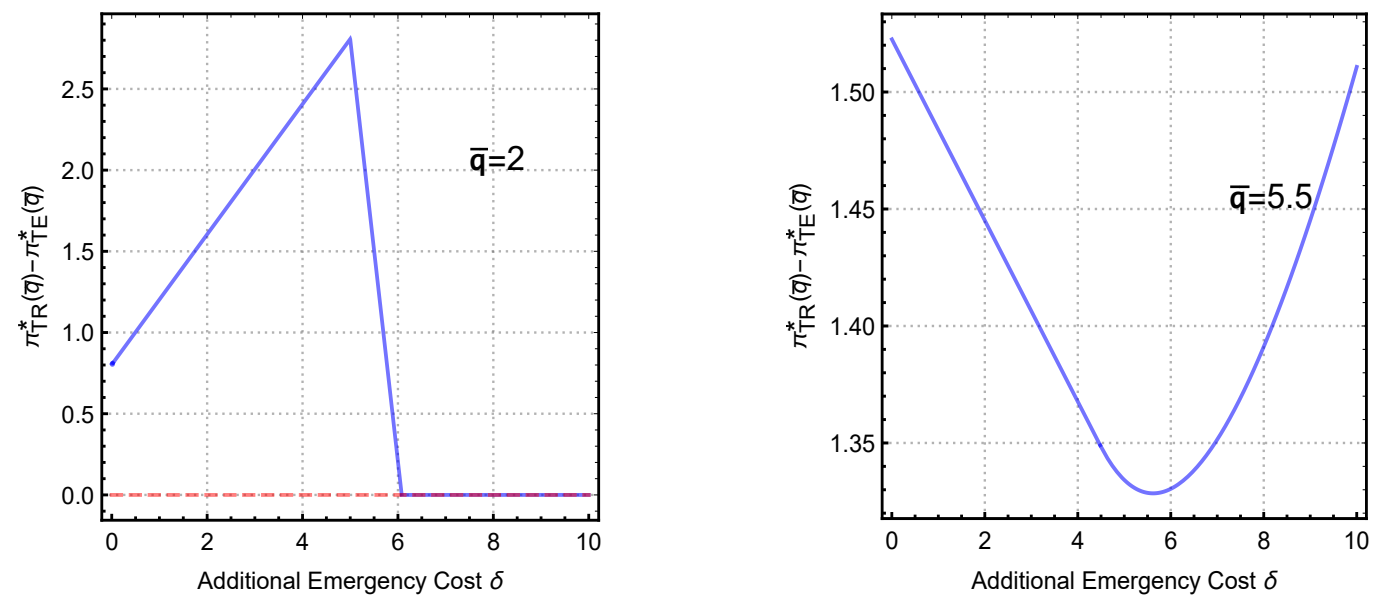

Figure 6. Profit difference $\pi_{\mathrm{TR}}^{*}(\bar{q})-\pi_{\mathrm{TE}}^{*}(\bar{q})$ in additional emergency cost $\delta$.

\subsection{Impact of Carbon Emission Quota}

The carbon emission quota plays a significant role in the energy supplier's expected profit. From Figure 7, we can find that in both cases of additional emergency cost $\delta=0.1$ and $\delta=2.5$, as the carbon emission quota increases, the expected profit under traditional energy first increases when the quota is lower than optimal coal inventory, and then becomes flat after the quota exceeds the optimal coal inventory. However, due to the restriction of carbon emission quota, the profit will be lower than that without any carbon restriction.

As is shown in Figure 8, we can find that, for given additional emergency cost $(\delta=0.1$ and $\delta=2.5$ ), the investment to the renewable energy is always beneficial to the energy supplier, and the TR strategy dominates the TE strategy. However, the additional emergency cost mediates the impact pattern of carbon emission quota to the expected profit difference. As is shown in Figure 9, the benefit from renewable energy maybe not monotone as carbon emission quota increases. Specifically, when the additional emergency cost is low $(\delta=0.1)$, the profit difference is quasi-concave in carbon emission quota, and if the carbon emission quota is low or high (for example, $\bar{q}<2$ or $\bar{q}>7$ ), the profit difference is a constant, and the benefit from renewable energy increases in carbon emission quota. However, this scenario varies when the additional emergency cost is high $(\delta=2.5)$, the benefit is quasi-convex, first decreases and then increases in carbon emission quota. 

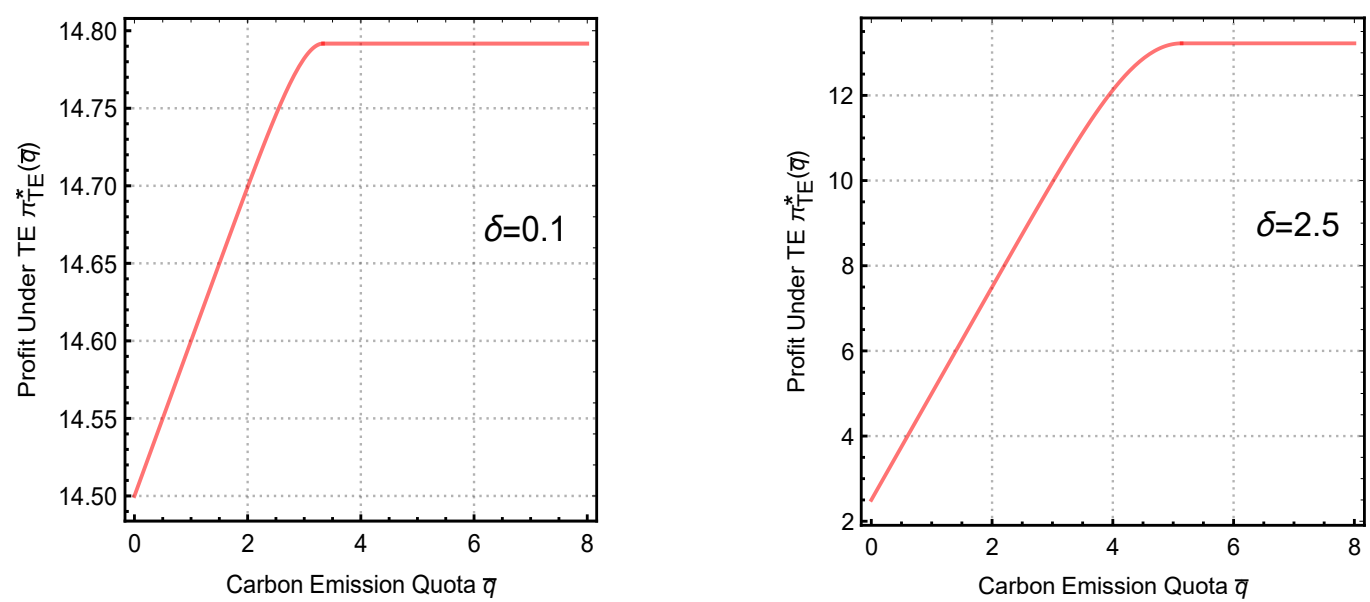

Figure 7. Expected profit under TE $\pi_{\mathrm{TE}}^{*}(\bar{q})$.
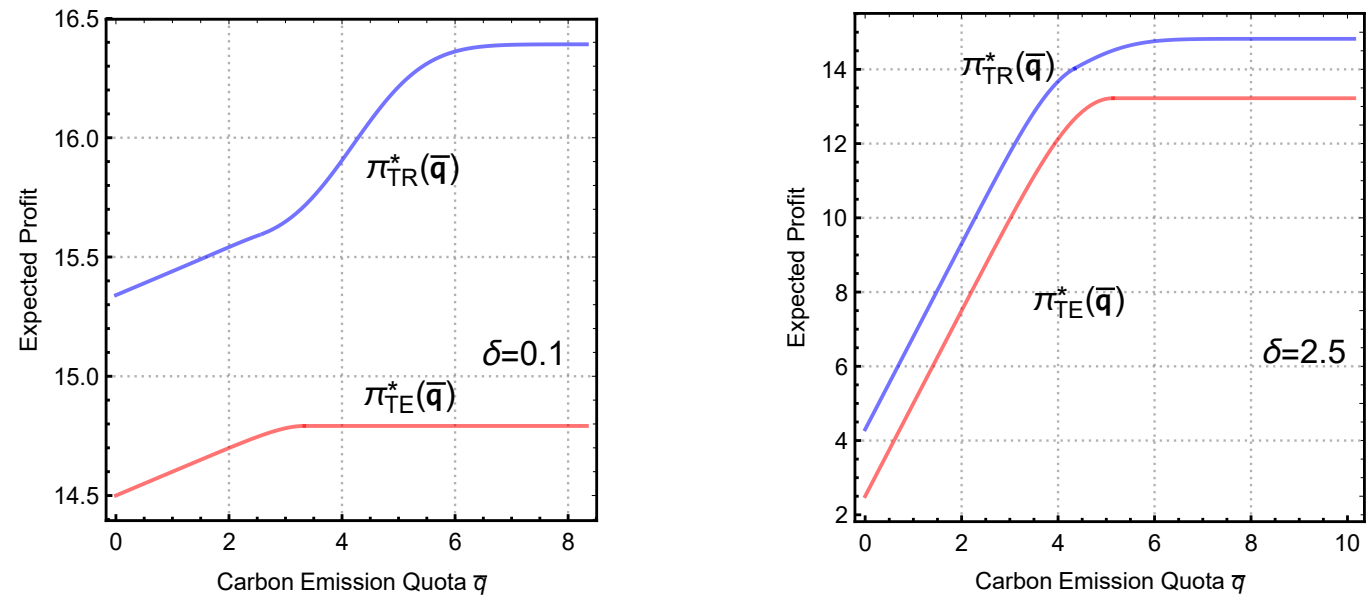

Figure 8. Expected profit $\pi_{\mathrm{TR}}^{*}(\bar{q})$ and $\pi_{\mathrm{TE}}^{*}(\bar{q})$ in carbon emission quota $\bar{q}$.
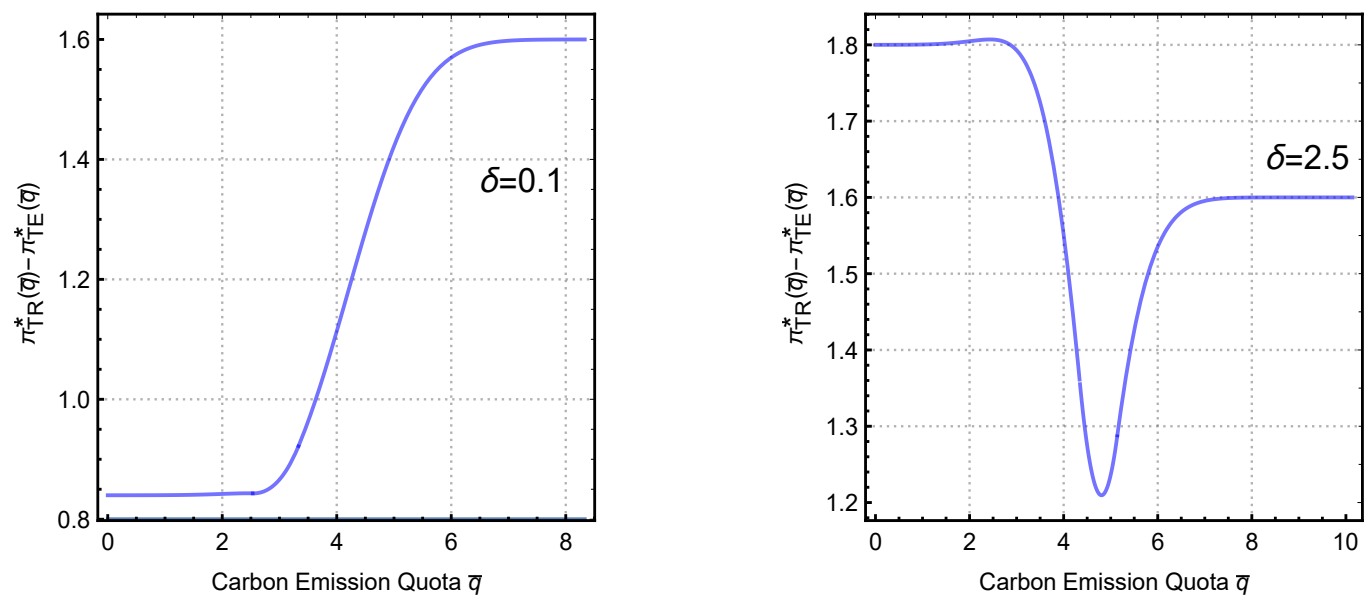

Figure 9. Profit difference $\pi_{\mathrm{TR}}^{*}(\bar{q})-\pi_{\mathrm{TE}}^{*}(\bar{q})$ in carbon emission quota $\bar{q}$.

\section{Conclusions}

This paper studies the investment to renewable energy capacity in the presence of emergency cost of coal supply and carbon emission quota, which is widely used by the government for controlling the greenhouse gas emission. By analyzing four cases, (1) traditional energy without carbon emission restriction; (2) traditional energy with carbon emission quota; (3) mixed energy (both traditional and 
renewable energy) without carbon emission restriction and (4) mixed energy with carbon emission quota, we arrive at the following outcomes.

Firstly, renewable energy establishment can mitigate the depression of carbon emission constraint. Therefore, by establishing renewable energy stations, emission-constrained energy supplier can replenish the electricity demand gap and attract some consumers with strong awareness of environmental protection. Secondly, negligible unit margin cost is an attractive advantage of renewable energy to energy supplier, who can obtain positive benefits from optimal mixed energy strategy if the additional emergency cost of traditional energy is not too high. That is, mixed energy strategy is always a better choice than (or weakly dominates) pure traditional energy strategy. Thirdly, the optimal renewable energy capacity level is decreasing in the carbon emission quota. For an emission-constrained energy supplier, the smaller emission quota it has, the larger renewable energy capacity will be established. Finally, our numerical simulations imply that the impact of additional emergency cost to the profit difference between mixed energy strategy and traditional energy strategy is mediated by carbon emission quota.

In the stream of renewable energy literature, the carbon emission trade system (see e.g., [25-28] for more detail) and the intermittence of renewable energy (see e.g., [29-33] for more detail) are often studied. However, we have not included these problems. Therefore, future work can focus on the carbon emission trade system, which will induce a much more complex problem if the energy supplier plans to establish renewable energy stations. Another further research direction is considering the impact of intermittence of renewable energy, which is a challenging work since the output of renewable energy is uncertain.

Author Contributions: Conceptualization, Y.Y. and F.C.; methodology, L.Y.; formal analysis, Y.Y., F.C. and L.Y.; writing-original draft preparation, L.Y.; writing-review and editing, Y.Y.; supervision, F.C.; project administration, F.C.; funding acquisition, Y.Y. All authors have read and agreed to the published version of the manuscript.

Funding: This research was funded by Key Project of University Humanities and Social Science in Anhui Province, No.SK2019A0102.

Conflicts of Interest: The authors declare no conflict of interest. The funders had no role in the design of the study; in the collection, analyses, or interpretation of data; in the writing of the manuscript, or in the decision to publish the results.

\section{Abbreviations}

The following abbreviations are used in this manuscript:

Summary of Model Notations

Parameterss

$D \quad$ demand of electricity market

$\mu \quad$ mean of $D$

$\sigma \quad$ standard deviation of $D$

$c \quad$ electricity unit margin cost (per KWH)

$\tilde{c} \quad$ unit emergency procurement cost (per KWH)

$\delta \quad=\tilde{c}-c$ unit additional emergency cost (per KWH)

$\bar{q} \quad$ ES's carbon emission quota given by regulation

$f \quad$ PDF of $D$

$F \quad$ CDF of $D$

$\bar{F} \quad=1-F, \mathrm{CCDF}$ of $D$

$\phi \quad$ PDF of $N(0,1)$

$\Phi \quad$ CDF of $N(0,1)$

$\bar{\Phi} \quad=1-\Phi$, CCDF of of $N(0,1)$

Decisions

$k_{s} \quad$ setup cost of renewable energy station with capacity $s$

$q_{\mathrm{TE}} \quad$ coal inventory under TE strategy

$q_{\mathrm{RE}} \quad$ coal inventory under RE strategy

$q_{\mathrm{TR}} \quad$ coal inventory under TR strategy 


\section{References}

1. Zhou, P.; Wen, W. Carbon-constrained firm decisions: From business strategies to operations modeling. Eur. J. Oper. Res. 2020, 281, 1-15. [CrossRef]

2. He, P.; Zhang, W.; Xu, X.; Bian, Y. Production lot-sizing and carbon emissions under cap-and-trade and carbon tax regulations. J. Clean. Prod. 2015, 103, 241-248. [CrossRef]

3. Gong, X.; Zhou, S.X. Optimal production planning with emissions trading. Oper. Res. 2013, 61, 908-924. [CrossRef]

4. Qin, J.; Zhao, Y.; Xia, L. Carbon Emission Reduction with Capital Constraint under Greening Financing and Cost Sharing Contracts. Int. J. Environ. Res. Public Health 2018, 15, 750. [CrossRef]

5. Kök, A.G.; Shang, K.; Yücel, S. Investments in Renewable and Conventional Energy: The Role of Operational Flexibility. Manuf. Serv. Oper. Manag. 2020, 2020. [CrossRef]

6. Hu, S.; Souza, G.C.; Ferguson, M.E.; Wang, W. Capacity investment in renewable energy technology with supply intermittency: Data granularity matters! Manuf. Serv. Oper. Manag. 2015, 17, 480-494. [CrossRef]

7. Sunar, N.; Birge, J.R. Strategic Commitment to a Production Schedule with Uncertain Supply and Demand: Renewable Energy in Day-Ahead Electricity Markets. Manag. Sci. 2019, 65, 714-734. [CrossRef]

8. Xie, J.; Wei, L.; Zhang, W.; Xia, Y.; Li, J. A Responsive Pricing Grid Operator Sourcing from Competing Generators under Uncertain Supply and Demand. Sustainability 2019, 11, 4061. [CrossRef]

9. Goodarzi, S.; Perera, H.N.; Bunn, D. The impact of renewable energy forecast errors on imbalance volumes and electricity spot prices. Energy Policy 2019, 134, 110827. [CrossRef]

10. Wang, W. Calculation on Net Value of Carbon Emission Transfer between China's Provinces and Responsibility Sharing. J. Environ. Econ. Chin. 2018, 3, 19-36.

11. Lv, J.; Zhang, Z. China's Provincial Carbon Emission Accounting Standards and Empirical Test. Stat. Decis. 2020, 2020, 1-6. (In Chinese)

12. Zhu, Q. A Perspective of Evolution for Carbon Emissions Trading Market: The Dilemma between Market Scale and Government Regulation. Discret. Dyn. Nat. Soc. 2017, 2017, 1-7. [CrossRef]

13. Da, B.; Liu, C.; Liu, N.; Xia, Y.; Xie, F. Coal-Electric Power Supply Chain Reduction and Operation Strategy under the Cap-and-Trade Model and Green Financial Background. Sustainability 2019, 11, 3021. [CrossRef]

14. Zhao, X.; Lyon, T.P.; Wang, F.; Song, C. Why do electricity utilities cooperate with coal suppliers? A theoretical and empirical analysis from China. Energy Policy 2012, 46, 520-529. [CrossRef]

15. Fan, J.L.; Ke, R.Y.; Yu, S.; Wei, Y.M. How does coal-electricity price linkage impact on the profit of enterprises in China? Evidence from a Stackelberg game model. Resour. Conserv. Recycl. 2018, 2018, 383-391. [CrossRef]

16. Ding, H.; Zhou, D.; Zhou, P. Optimal policy supports for renewable energy technology development: A dynamic programming model. Energy Eco. 2020, 104765. [CrossRef]

17. Parker, G.G.; Tan, B.; Kazan, O. Electric power industry: Operational and public policy challenges and opportunities. Prod. Oper. Manag. 2019, 28, 2738-2777. [CrossRef]

18. Zhang, J.; Xu, Y. Research on the Price Fluctuation and Risk Formation Mechanism of Carbon Emission Rights in China Based on a GARCH Model. Sustainability 2020, 12, 4249. [CrossRef]

19. Busu, M. The role of renewables in a low-carbon society: Evidence from a multivariate panel data analysis at the eu level. Sustainability 2019, 11, 5260. [CrossRef]

20. Zou, S.; Zhang, T. Multifractal Detrended Cross-Correlation Analysis of Electricity and Carbon Markets in China. Math. Probl. Eng. 2019, 2019, 9350940. [CrossRef]

21. Xie, J.; Li, J.; Liang, L.; Fang, X.; Yang, G.; Wei, L. Contracting Emissions Reduction Supply Chain Based on Market Low-Carbon Preference and Carbon Intensity Constraint. Asia-Pac. J. Oper. Res. 2020, 37, 1-34. [CrossRef]

22. Lariviere, M.A.; Proteus, E.L. Selling to the Newsvendor: An Analysis of Price-Only Contracts. Manuf. Serv. Oper. Manag. 2001, 3, 293-305. [CrossRef]

23. Dada, M.; Hu, Q. Financing newsvendor inventory. Oper. Res. Lett. 2008, 36, 569-573. [CrossRef]

24. Lai, G.; Debo, L.; Sycara, K. Sharing inventory risk in supply chain: The implication of financial constraint. Omega 2009, 37, 811-825. [CrossRef]

25. Yang, L.; Hu, Y.; Huang, L. Collecting mode selection in a remanufacturing supply chain under cap-and-trade regulation. Eur. J. Oper. Res. 2020, 287, 480-496. [CrossRef] 
26. Xu, X.; He, P.; Xu, H.; Zhang, Q. Supply chain coordination with green technology under cap-and-trade regulation. Int. J. Prod. Econ. 2017, 183, 433-442. [CrossRef]

27. Dong, C.; Shen, B.; Chow, P.S.; Yang, L.; Ng, C.T. Sustainability investment under cap-and-trade regulation. Ann. Oper. Res. 2016, 240, 509-531. [CrossRef]

28. Sheu, J.B.; Li, F. Market competition and greening transportation of airlines under the emission trading scheme: A case of duopoly market. Transp. Sci. 2014, 48, 684-694. [CrossRef]

29. Aflaki, S.; Netessine, S. Strategic investment in renewable energy sources: The effect of supply intermittency. Manuf. Serv. Oper. Manag. 2017, 19, 489-507. [CrossRef]

30. Xie, J.; Zhang, W.; Wei, L.; Xia, Y.; Zhang, S. Price optimization of hybrid power supply chain dominated by power grid. Ind. Manag. Data Syst. 2019, 119, 412-450. [CrossRef]

31. Yenipazarli, A. Incentives for environmental research and development: Consumer preferences, competitive pressure and emissions taxation. Eur. J. Oper. Res. 2019, 276, 757-769. [CrossRef]

32. Xie, J.; Li, Z.; Xia, Y.; Liang, L.; Zhang, W. Optimizing capacity investment on renewable energy source supply chain. Comput. Ind. Eng. 2017, 107, 57-73. [CrossRef]

33. Baranes, E.; Jacqmin, J.; Poudou, J.C. Non-renewable and intermittent renewable energy sources: Friends and foes? Energy Policy 2017, 111, 58-67. [CrossRef]

(C) 2020 by the authors. Licensee MDPI, Basel, Switzerland. This article is an open access article distributed under the terms and conditions of the Creative Commons Attribution (CC BY) license (http:/ / creativecommons.org/licenses/by/4.0/). 